Victor Faria Blanc FRCP(c), Jean-François Hardy MD, Jean Milot frCs(C), Jean-Louis Jacob FrCs(c)

\title{
The oculocardiac reflex: a graphic and statistical analysis in infants and children
}

A new method for the detection and recording of the oculocardiac reflex (OCR) is described and applied so 49 healthy infants and children (six months to nine years old) undergoing strabismus surgery under holothane anaesthesia with spontaneous ventilation. Eighty-one extraocular muscles were studied. Square wave stimuli (abrupt and sustained tractions) were definitely more reflexogenic than slow slope srimuli (very gradual, progressive and gentle tractions). Vagal escape, as well as fatigue of the $O C R$, are graphically documented and analysed. In this series, using well-defined and controlled tractions, the medial rectus was not more reflexogenic than the other extraocular muscles. Hypercapnia was an important adjuvant factor of the OCR. Controlled ventilation is recommended. The routine use of intravenous anticholinergic drugs is briefly discussed. Prevention of the $O C R$, and prophylaxis of cardiac arrinythmias during strabismus surgery, now seem to be placed on a more rational basis.

\section{Key words}

OCULOCARDIAC REFLEX; SURGERY, strabismus; ANAESTHESIA, paediatric; VAGAL escape; ARRHYTHMIAS, Cardiac; ANTICHOLINERGIC, antimuscarinic drugs; HYPERCAPNIA.

From the Departments of Anaesthesia and Ophthalmology, Hôpital Sainte-Justine and Université de Montreal, Montréal, Québec.

Address correspondence to: Victor Farja Blanc MD, Department of Anaesthesia, Hôpital Sainte-Justine, 3175 Chemin Ste-Catherine, Montréal, Québec, Canada H3T 1 C5.

Presented in part at the Annual Meeting of the Canadian Ophthalmological Society, Toronto, June 29, 1982.

Supported in part by Research Grant 862 from La Fondation Justine-Lacoste-Beaubien (Hôpital SainteJustine, Montréal).
The oculocardiac reflex (OCR) was first described in 1908 by Aschner and by Dagnini, ${ }^{2}$ in two simultaneous but independent reports. Since then, an abundant bibliography has been accumulated, particularly in journals of cardiology, ophthalmology and anaesthesiology. ${ }^{3}$

The OCR is trigeminovagal (Figure 1). Sectioning of the optic, oculomotor, trochlear and abducens nerves in the orbit do not eliminate the reflex, thereby establishing the ophthalmic branch of the Vth cranial nerve as the afferent pathway. ${ }^{4-6}$

The OCR can be evoked by pressure on the ocular globe, traction on the extrinsic muscles of the eye, intraorbital injections or haematomas, acute glaucoma, and stretching of the eyelid's muscles (blepharocardiac reflex, in the Marcus Gunn syndrome). ${ }^{3.7 .8}$

The cardiac manifestations of the OCR include sinus bradycardia and cardiac arrhythmias. Prolonged OCR has been reported in patients with orbital haemorrhage, after enucleation of the eye, and after ocular trauma. ${ }^{9,10}$

Most studies have dealt with the OCR resulting from traction on the extraocular muscles during correction of strabismus. The incidence of the OCR, in this type of surgery, ranges from 32 to 90 per cent, depending upon the methods used and the criteria of evaluation chosen. ${ }^{11-13}$

Transient cardiac arrest could be as frequent as $1 / 2,200$ corrections of strabismus. ${ }^{14}$ More than 60 deaths have been related to the OCR, even during use of local anaesthesia. ${ }^{15-17}$ Sino-atrial arrests were mentioned. ${ }^{18}$ Though rare, ventricular fibrillation has been reported. ${ }^{19,20}$

The following study introduces a graphic and statistical analysis of the OCR in infants and children undergoing squint surgery. It is centred around four basic questions:

(a) How important is the specific type of stimulus 


\section{OCULOCARDIAC REFLEX PATHWAYS}

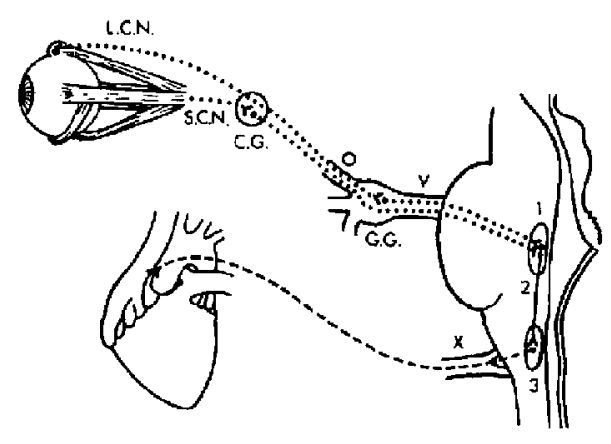

FIGURE 1 Afferent pathway (․): long ciliary norves (LCN) and short ciliary nerves (SCN); ciliary ganglion (CG); ophthalmic branch of the Vth cranial nerve (O); Gasserian ganglion (GG); main sensory nucleus of the trigeminal nerve (1)

Short internuncial ffbres (-) in the reticular formation (2).

Efferen pathway (---): motor nucleus of the vagus nerve (3) cardiac depressor nerve from the Xth cranial nerve $(X)$; ends in the muscular tissue of the heart.

in the incidence of the OCR, in the occurrence of cardiac arrhythmias, and in causing fatigue of the OCR?

(b) How operative is the vagal escape mechanism?

(c) How important are predisposing and adjuvant factors of the OCR (age; sex; specific extraocular muscle stimulated; acid-base status; initial heart rate)?

(d) What should be done to prevent or minimize the OCR and the occurrence of cardiac arrhythmias?

\section{Methods}

Subjects - Forty-nine infants and children (six months to nine years old; ASA physical status I) requiring correction of strabismus under general anaesthesia were studied after informed consent was obtained from the parents. The protocol for this study was approved by the Committee on Medical Ethics of the Hôpital Sainte-Justine. Eighty-one extraocular muscles were operated on and studied: 49 medial recti ( 60.5 per cent); 21 lateral recti (25.9 per cent); nine inferior obliques (11.1 per cent); and two superior recti ( 2.5 per cent). Of these muscles, 53.1 per cent were from males and 46.9 per cent were from females; 45.7 per cent were right extraocular muscles and 54.3 per cent were left muscles. Infants (6-12 months old) contributed to 33 per cent of the muscles studied.

Anaesthetic technique - Infants were fasted six to eight hours, and premedicated with intramuscular atropine $\left(0.01 \mathrm{mg} \cdot \mathrm{kg}^{-1}\right)$. Children were fasted 814 hours, and received atropine sulfate $(0.01 \mathrm{mg}$. $\left.\mathrm{kg}^{-1}\right)$, meperidine $\left(1 \mathrm{mg} \cdot \mathrm{kg}^{-1}\right)$, and hydroxyzine (1 $\mathrm{mg} \cdot \mathrm{kg}^{-1}$ ), by the intramuscular route, approximately 45 minutes before anaesthesia. Induction was achieved with halothane, nitrous oxide and oxygen ( 50 per cent) by mask. All patients received five per cent glucose in $0.2 \mathrm{~N}$ saline $\left(5 \mathrm{ml} \cdot \mathrm{kg}^{-1}\right.$. hour $^{-1}$ ) intravenously. Tracheal intubation was performed without the use of muscle relaxants under deep halothane-oxygen anaesthesia. After intubation, anaesthesia was maintained with halothane (one per cent), nitrous oxide ( 60 per cent) and oxygen ( 40 per cent), using a Bain circuit with a fresh gas flow not less than $260 \mathrm{ml} \cdot \mathrm{kg}^{-1}$, with spontaneous breathing.

Monitoring - Precordial stethoscope; continuous ECG (lead II) with cardiotachometer; regular blood pressure measurements with an Arteriosonde 1010 (Doppler principle); rectal thermometry. Arterial blood gases and acid-base status were evaluated in 39 patients, 20 minutes after tracheal intubation.

Surgical technique - Consisted of a curvilinear conjunctival incision of the Tenon's capsule, according to the muscle to be operated upon, with minimal mobilization of the globe in order not to elicit the OCR. Secondly, a muscle hook was engaged under the muscle tendon. A 4-0 silk suture loop was slipped under the hook, keeping the dissection minimal and thus avoiding traction on the muscle to be studied.

Equipment and measurement technique - The silk suture loop was connected to a microdisplacement myograph transducer hand-held by the surgeon. The configuration of the equipment used for the detection and recording of the OCR is shown in Figure 2. Calibrations were such that the graph paper moved at a constant speed of $1 \mathrm{~mm} \cdot \mathrm{sec}^{-1}$; heart rate deflections of $1 \mathrm{~mm}$ (downward or upright) equaled variations of 2.4 beats $\cdot \mathrm{min}^{-1}$; each pulling force of 50 grammes corresponded to a 5 millimeters height displacement. The system could detect forces from 0 to 1000 grammes with a precision of 5 grammes.

Graphic procedure and analysis - Three dif- 


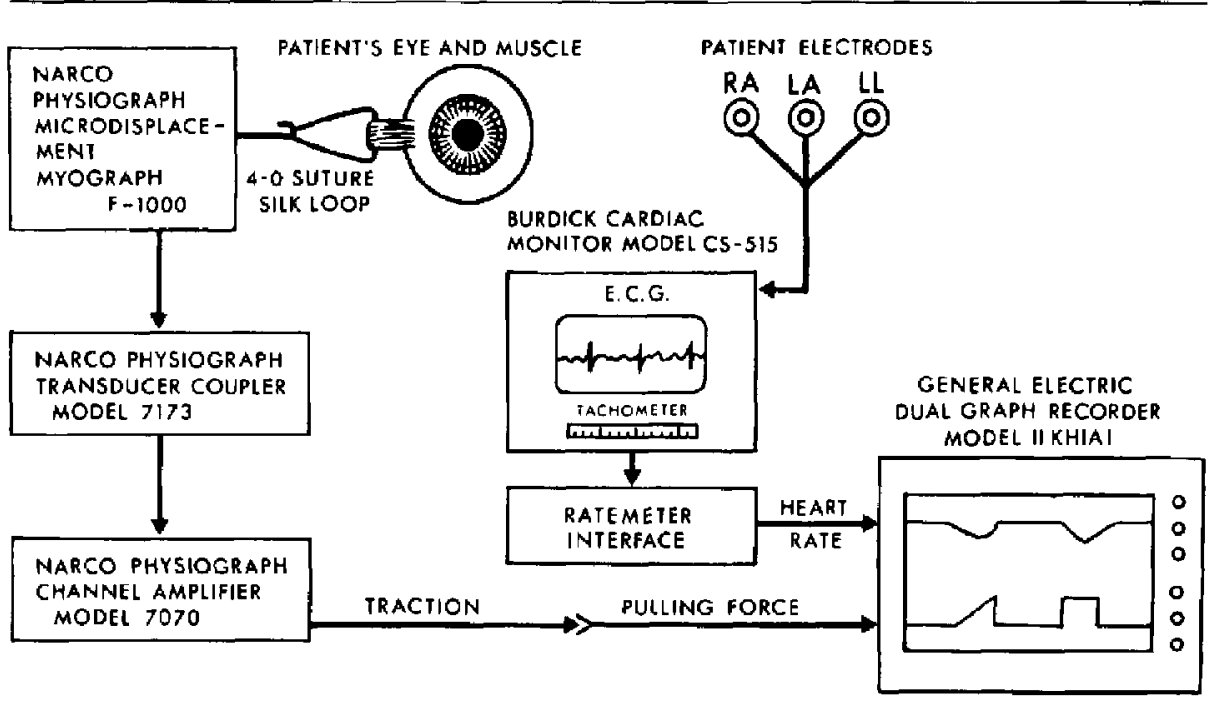

FIGURE 2 Configuration of the equipment for the detection and recording of the oculocardiac reflex.

ferent types of stimuli were selected for this study (Figure 3):

Type A (square wave (SW) stimuli) - Acute traction equal or more than 150 grammes (maximum $=300$ grammes), sustained for a minimum of 20 seconds, followed by acute release.

Type B (slow slope (SS) stimuli) - Smooth or slow gradual traction until reaching a peak not less than 150 grammes (maximum $=300$ grammes) and making an angle not greater than $\mathbf{4 5}$ degrees with the base line, followed by acute release.

Type C (fast slope (FS) stimuli) - Rapid progressive traction until a peak not less than 150 grammes (maximum $=300$ grammes) and making an angle greater than 45 degrees with the base line, then followed by an acute or very rapid release.

No more than two equal or different stimuli were applied to each muscle. Median time between two successive stimuli was 47 seconds (range: 11-99 seconds).

Positive OCR was considered to have occurred when the heart rate slowed at least 7.2 beats $\mathrm{min}^{-1}$ ( $3 \mathrm{~mm}$ recotded downward deflection).

Fatigue of the OCR was considered present when the response to the first stimulus exceeded that of the second stimulus by 7.2 beats $\mathrm{min}^{-1}(3 \mathrm{~mm})$ or more. Fatigue of the OCR was ill-defined when this

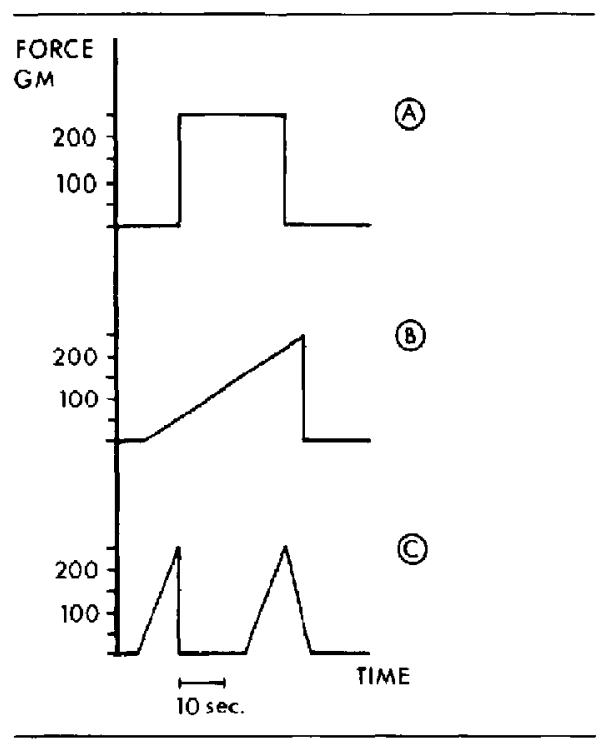

FIGURE 3 The three different types of stimuli employed in this study. See text for details.

difference did not exceed 4.8 beats $\cdot \min ^{-1}(2 \mathrm{~mm})$. Finally, fatigue was clearly absent when the response to the second stimulus was superior to that of 


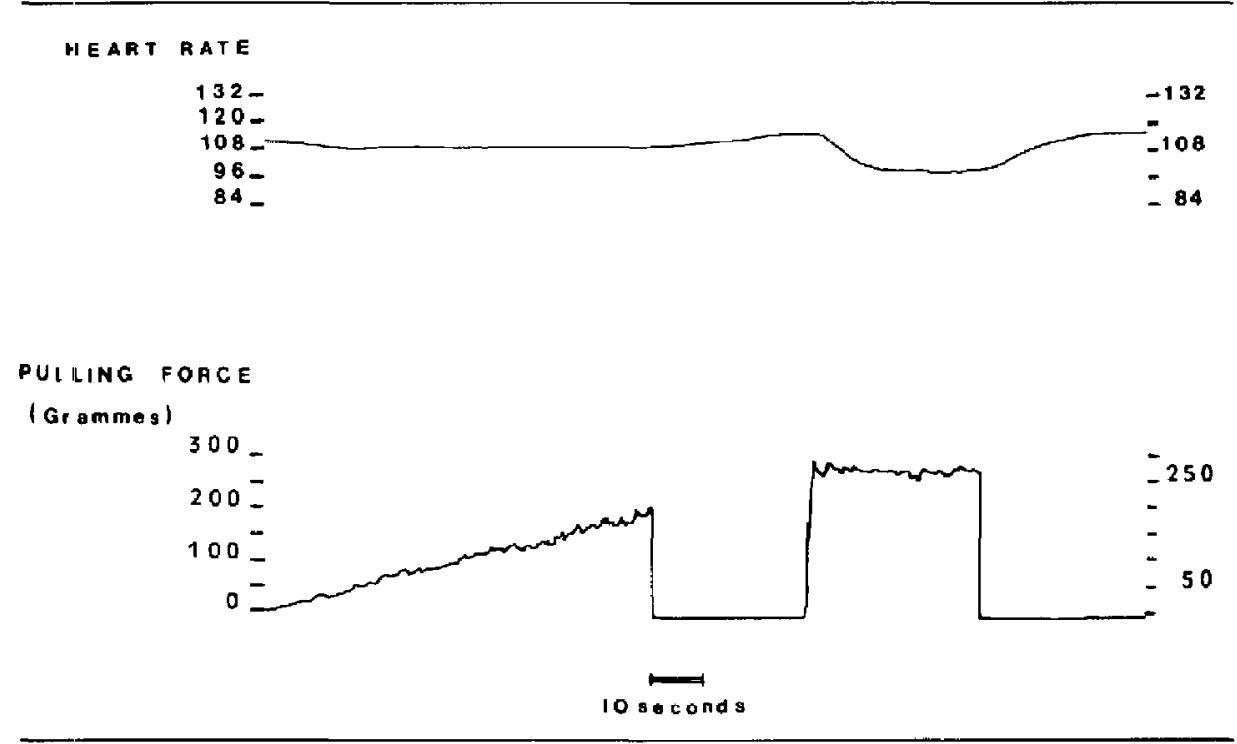

FIGURE 4 The first stimulus (type B; smooth and gentle traction) fails to produce the OCR. The second stimulus (type A: abrupt and sustained traction) elicits the OCR. (Obtained from the left lateral rectus of a nine-year-old girl.)

the first stimulus by 7.2 beats $\cdot \mathrm{min}^{-1}(3 \mathrm{~mm})$ or more.

Vagal escape was identified when the bradycardia spontaneously regressed in spite of the fact that the pulling force stayed constant (plateau phase) (Figure 5).

The occurrence of cardiac rhythms other than sinus bradycardia was also noted.

Statistical analysis - Statistical calculations were made with the aid of the Centre de Calcul de l'Université de Montréal. Comparative analysis of data was made using either the Fisher's exact test or the Chi-square test. $\mathbf{P}<0.05$ was considered statistically significant.

\section{Results}

Type of first stimulus and incidence of the $O C R$ Analysis of 64 first tractions revealed that the type A (SW) stimulus was significantly more reflexogenic than the type B (SS) stimulus, regardless of other considerations (Table I). The type C (FS) stimulus was a hybrid or ill-defined form of stimulation (57 per cent of positive responses).

Graphic analysis in the same muscle of the same eye showed that the type A stimulus could be more highly reflexogenic than the type $B$ stimulus.
TABLE I Type of first stimulus and incidence of the OCR

\begin{tabular}{llll}
\hline \multirow{2}{*}{$\begin{array}{l}\text { Type of first } \\
\text { stimulus }\end{array}$} & \multicolumn{2}{l}{ Percentage of responses } \\
\cline { 2 - 4 } & Positive & Negative & $N$ \\
\hline $\mathrm{A}-\mathrm{B}$ & 86.7 & 13.3 & 15 \\
$\mathrm{~B}-\mathrm{51.0}$ & 49.0 & 49 \\
\hline
\end{tabular}

$P=0.03$.

Moreover, a very gradual (SS) traction often failed to evoke the OCR (Figure 4).

Type of first stimulus and fatigue of the OCR The significance of the type of first stimulus in causing fatigue of the OCR was considered on 68 extraocular muscles. For this purpose, two successive stimuli were applied to each muscle with a median interval of time of 47 seconds (range: 11-99 seconds). The second applied traction was standardized as a type A (SW) stimulus (the more reflexogenic one). On the contrary, the first traction was produced at random as one of the three different types of stimulus represented in Figure 3. So, three different combinations of two successive stimuli were compared (Table II).

Fatigue was significantly more frequent when the 

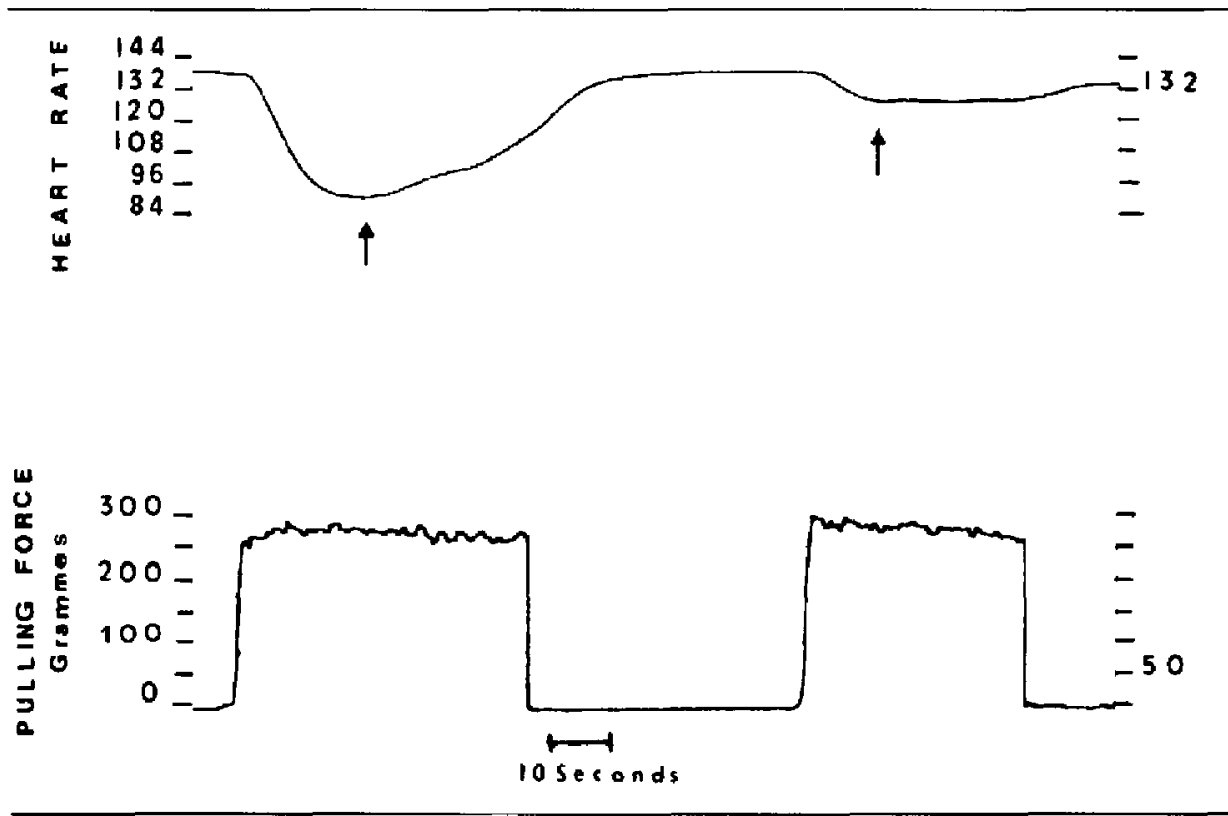

FIGURE 5 Vagal escape indicated by arrows under the heart rate tracing. Fatigue of the OCR manifested by lcss intense slowing of the heart rate and shorter interval of time for vagal escape during the second square wave stimulus. (Obtained from the right lateral rectus of a 12 -month-old male infant.)

TABLE II Type of first stimulus and fatigue of the OCR

\begin{tabular}{|c|c|c|c|c|}
\hline \multirow{2}{*}{$\begin{array}{l}\text { Combinations of } \\
\text { stimuli }\end{array}$} & \multicolumn{3}{|c|}{ Degree of fatigue } & \multirow[b]{2}{*}{$N$} \\
\hline & Present & Ill-defined & Absent & \\
\hline A & $60 \%$ & $40 \%$ & $0 \%$ & 10 \\
\hline B. & $13.7 \%$ & $72.7 \%$ & $13.6 \%$ & 44 \\
\hline $\mathrm{C}$ & $7.2 \%$ & $71.4 \%$ & $21.4 \%$ & 14 \\
\hline
\end{tabular}

$P=0.0078$.

$\%=$ Percentage of cases presenting a given degree of fatigue caused by the first stimulus ( $A, B$ or $C$ )

first muscular traction corresponded to the type A stimulus. Furthermore, fatigue was never absent with this same type of first stimulation.

Vagal escape - Type B stimuli (SS), tended to produce a gradual slowing of the heart rate, but type A stimuli (SW) instead elicited a bradycardia whose tendency was to fade, or to regress, even while the pulling force stayed constant (plateau phase) (Figure 5). Vagal escape occurred normally at a mean time of 15.5 seconds (range: $7-25$ seconds) following the arousal of bradycardia by a first stimulation. Fatigue reduced the intensity of the bradycardia and shortened the interval of time for vagal escape during the second traction (Figure 5).

Predisposing and adjuvant factors of the $O C R$ Age - Neither of the three types of stimulus caused a statistical difference in the incidence of the OCR, when infants (6-12 months) were compared with children.

Sex - This was not a significant factor in influencing the OCR.

Type of muscle stimulated - Statistical comparisons made between 49 medial recti and 32 other extraocular muscles revealed that there was no significant difference observed in either the percentage of positive responses or the intensity of these responses (degree of bradycardia), when the same type of first stimulus was used. Furthermore, direct graphic comparison between the medial rectus and the lateral rectus in the same eye was achieved in two six-year-old males. No difference was noted in the intensity of the OCR elicited on the two muscles of the same eye, when the same type of stimulus 
TABLE lII $\mathrm{PaCO}_{2}$ and incidence of the OCR with the least reflexogenic of stimuli (Type B or $\mathbf{S S}$ stimulus)

\begin{tabular}{|c|c|c|c|}
\hline \multirow{2}{*}{$\begin{array}{l}\mathrm{PaCO}_{2} \\
\mathrm{KPa}(\mathrm{mmHg})\end{array}$} & \multicolumn{2}{|c|}{ Percentage of responses } & \multirow[b]{2}{*}{$N$} \\
\hline & Positive & Negative & \\
\hline \multicolumn{4}{|l|}{$3.5-5.2$} \\
\hline$(26-39)$ & 34.8 & 65.2 & 23 \\
\hline \multicolumn{4}{|l|}{$5.3-7.3$} \\
\hline$(40-5.5)$ & 75.0 & 25.0 & 16 \\
\hline
\end{tabular}

was employed. Consequently, in this series, the medial rectus was not more reflexogenic than the other extraocular muscles exposed to the same stimulus.

The only difference we could find was that the OCR induced via the medial rectus tended to be more resistant to fatigue than the OCR elicited via the other extraocular muscles $(P=0.06)$.

As far as laterality is concerned, we found no statistical difference in the incidence of positive responses according to the type of stimulus between the right and the left eye muscles.

Arterial blood gases and acid-base status - In the five minutes preceding the extraocular muscle stimulation, mean arterial $\mathrm{pH}$ was 7.31 (range: 7. 18-7.40); mean $\mathrm{PaCO}_{2}$ was $5 \mathrm{kPa}(38 \mathrm{mmHg})$ (range: $3.5-7.3 \mathrm{kPa} ; 26-55 \mathrm{mmHg}$ ); mean base excess was $-6.3 \mathrm{nmol} /$ itre (range: +1 to $-12.6 \mathrm{nmol}$ litre), mean $\mathrm{PaO}_{2}$ was $16.3 \mathrm{kPa}$ (122.6 $\mathrm{mmHg}$ ) (range: $8.1-20.9 \mathrm{kPa} ; 61-157 \mathrm{mmHg}$ ). Seven patients developed mixed acidosis $\left(\mathrm{PaCO}_{2}\right.$ between $5,9-7.3 \mathrm{kPa} ; 44-55 \mathrm{mmHg}$ ) and nine patients presented some degree of hypoxaemia $\left(\mathrm{PaO}_{2}\right.$ between $8.1-12.8 \mathrm{kPa} ; 61-96 \mathrm{mmHg}$ ).

No statistical differences were found when the incidence of the OCR was considered together with isolated variations of the arterial $\mathrm{pH}$ or $\mathrm{PaO}_{2}$, and with each one of the different types of stimulus. High levels of $\mathrm{PaCO}_{2}$ (greater than $5.3 \mathrm{kPa}$; $40 \mathrm{mmHg}$ ) significantly augmented the incidence of the OCR when the least reflexogenic stimulus (type $B$ or SS) was used (Table III).

Direct graphic analysis showed that the intensity of the OCR was particularly notable in two of three patients presenting mixed acidosis associated with unexpected hypoxaemia. None of these patients developed cardiac arrhythmias.

Initial heart rate - The base line heart rate (recorded before starting muscular stimulation; range: $96-166$ beats $\mathrm{min}^{-1}$ ) was not associated with a statistical difference in the incidence of the OCR. However, high initial heart rates (141-166 beats $\left.\min ^{-1}\right)$ were associated with a significant smaller response to the second stimulus, when compared with lower heart rates (102-122 beats. $\left.\min ^{-1}\right)(P=0.03)$.

Cardiac arrhythmias - Nodal thythms were noted in five patients. Three ectopic ventricular beats, following a nodal bradycardia, were found in one patient. Ventricular bigeminy occurred in another patient, for a total of seven cardiac arrhythmias in 49 patients (14.3 per cent). Arrhythmias often persisted beyond the bradycardia, for as long as three minutes and 40 seconds, after the stimulus was released. No correlation could be established between the acid-base status and the incidence of arrhythmias. Type A stimulus and type B stimulus were equally responsible for the nodal rhythms. Ventricular bigeminy was related to the type A stimulus.

\section{Discussion}

The type of stimulus: a determinant factor in the incidence of the $O C R$ - Except for Dewar and Wishart, ${ }^{12}$ and for Sold, Rothhammer and Schäfer, ${ }^{21}$ previous investigators had not estimated the degree of traction applied to the extraocular muscles. In this study, we not only recorded the pulling force in grammes but we also investigated the physiological consequences of three different types of stimuli on the cardiac rate simultaneously recorded with the aid of a tachometer (Figures 2 and 3). This new approach permitted some insights into the understanding of the OCR during strabismus surgery.

The type of stimulus clearly influences the incidence of the OCR, the acute and sustained stimulus (type $A$ ) being more reflexogenic. Therefore, the best prevention of the OCR consists in avoiding precipitate and aggressive manipulation of the extraocular muscles (Figure 4). Alexander, ${ }^{22}$ had suspected the real importance of the type of stimulus. He noted that the mean cardiac slowing was of 49 beats $\mathrm{min}^{-1}$ in the first twenty, and only 16 beats $\mathrm{min}^{-1}$ in the last twenty non-atropinized patients of his series $(P=0.05)$. Alexander's conclusion is that the surgeon was being more gentle when he realized the effect he could produce. A few authors stress the importance of a delicate 
operating technique. ${ }^{3,5,11}$ This study demonstrates it.

The type of stimulus: a determinant factor causing vagal escape and fatigue of the $O C R$ - Some confusion has arisen in the medical literature because of the indiscriminate use of the term fatigue, when dealing with the OCR.

Vagal escape (sometimes incorrectly called fatigue) is related to the promptness with which the motor nucleus of the vagus tends to become refractory to a sustained stimulus. Vagal escape explains why the conscious animal usually takes no more than some seconds to spontaneously recover from a cardiac arrest produced by vagal stimulation. ${ }^{6}$ Vagal escape explains in part why some anaesthetized humans can be recovered from sinoatrial arrest. ${ }^{18}$

The equipment we used for the detection and recording of the OCR made it clear that vagal escape occurred very often when the type A stimulus elicited a positive OCR (Figure 5 ). The mean time for vagal escape in this series (15.5 seconds; range: $7-25$ seconds) corresponds roughly to the mean maximum slowing rate defined by Moonie, Rees and Elton in $1964 .^{23}$

Fatigue of the $O C R$ depends on the period of time during which the central nucleus of the vagus stays relatively refractory to repetitive stimulation. Fatigue reduced the intensity of the bradycardia and shortened the interval of time for vagal escape following a second stimulation (Figure 5). Moonie et al. ${ }^{23}$ state that the signs of fatigue are not present when the intervals of rest between two successive stimuli are greater than $20-30$ seconds. We observed fatigue at intervals of rest as long as 76 seconds.

Vagal escape and fatigue of the OCR are physiologic mechanisms of defense against excessive vagal stimulation. These mechanisms may be more or less obtunded by general anacsthesia.

Predisposing and adjuvant factors of the $O C R$ In infants and children (six months to nine years old), age and sex play no significant role in the incidence of the OCR.

It is commonly admitted that the medial rectus is more highly reflexogenic than the other extraocular muscles. Using controlled and well-defined stimuli, our results do not confirm such a statement. Welhaf and Johnson, ${ }^{24}$ performed a recession-resection procedure on the horizontal muscles of six patients with resulting bradycardia from the lateral rectus alone, in one patient. Deacok and $\mathrm{Oxer}^{25}$ are other authors who could not find a greater incidence of the OCR on the medial rectus.

A few logical arguments could explain these discrepant results concerning the medial rectus:

(a) The present series deals with infants and children (six months to nine years old) whereas several important papers extend the age range from 5-18 months to 65-92 years. . $^{6,16,26-28}$

(b) Methods and criteria of evaluation used in previous studies appear to be less precise than the simultaneous recording of the pulling force and of the heart rate.

(c) Convergent strabismus is far more frequent than the other forms of strabismus, and so the medial rectus is more often manipulated than the other extraocular muscles.

(d) The medial rectus is somewhat less accessible than the lateral rectus. Consequently, non-controlled pulling forces could be greater on the medial recti.

(e) One published series points out that the lateral rectus muscle was operated on first and its manipulation caused the more profound bradycardia. ${ }^{22}$ In another published series, all patients with convergent squint ( 90 per cent) had the medial rectus operated first and the conclusion was that the medial rectus is more sensitive. ${ }^{28}$

However, the medial recti of our series tended to be more refractory to fatigue than the other extrinsic muscles of the eye $(P=0.06)$. More wellcontrolled studies are still needed on this subject.

In our series, no statistical difference was found in the incidence of the OCR when related to the laterality of the extraocular muscles. Left and right muscles caused identical responses to identical stimuli.

Most patients presented metabolic acidosis. This is an important problem, particularly in paediatric hospitals confronted with busy operative schedules. Efforts must be attempted to bring the periods of fast to more reasonable proportions, even if the arterial $p H$, by itself, does not seem to change the incidence of the OCR.

Most important is the finding that high $\mathrm{PaCO}_{2}$ more than doubled the percentage of significant bradycardia when the least reflexogenic of stimuli (type B) were employed (Table III). This brings the discussion to the type of ventilation to be chosen 
during general anaesthesia for strabismus surgery. Anaesthesia under spontaneous ventilation has been largely practiced in, and even recommended for the correction of strabismus in infants and children. ${ }^{6,12,28-30}$ Our results favour the choice of controlled ventilation, in order to reduce the incidence of the OCR. Inasmuch as Pöntinen ${ }^{6}$ proved that controlled ventilation terminates reflexly induced cardiac and respiratory arrests, manually controlled ventilation should at least be practiced immediately before and during the extraocular muscle traction.

In our group of paediatric patients receiving no intravenous antimuscarinic medication, high initial heart rates $\left(141-166\right.$ beats $\cdot \mathrm{min}^{-1}$ ) showed no protective effect against the OCR elicited by a first stimulation. But these same high initial heart rates seemed to facilitate the fatigue of the OCR, when compared to the lower initial heart rates (102-122 beats $\left.\min ^{-1}\right)$. So, a question remains. How justifiable is routine use of intravenous antimuscarinic drugs for the prevention of the OCR?

Schwartz ${ }^{5}$ gives an unequivocal answer. There is no justification for using systematic intravenous atropine in children undergoing correction of strabismus, for three reasons. Intravenous atropine causes a high incidence of both premature ventricular contractions and runs of bigeminy. Also, unlike bradycardia, cardiac arrhythmias do not disappear immediately upon the release of traction. Finally, ventricular arrhythmias are of a more disturbing nature than the bradycardia that has been prevented. Moreover, with halothane anaesthesia there is a 17 per cent incidence of ventricular arrhythmias on intravenous atropine. ${ }^{31}$ Nonetheless, several authors postulate the prophylactic virtues of intravenous atropine and glycopyrrolate. ${ }^{6,12,28,32,33}$

The present study was not designed to determine the safety and the prophylactic effectiveness of intravenous antimuscarinic drugs. But it proved to us that intramuscular atropine associated with gentle (or more physiological) manipulation of the extraocular muscles can reduce the intensity of the OCR, as well as the occurrence of cardiac arrhythmias, to very acceptable levels and can provide a way of avoiding the potential risks inherent to the routine use of intravenous anticholinergics. Mirakhur and Jones ${ }^{33}$ state that anticholinergics administered intramuscularly reduce the incidence of the OCR from 90 to 50 per cent.
We believe that safe alternatives to the routine use of intravenous antimuscarinics must be investigated (especially for those patients for whom anticholinergics may be harmful). The ideal routine should be the routine of the proper choice, for the proper patient, in proper circumstances.

The prevention of the $O C R$ and of cardiac arrhythmias during strabismus surgery - The type of stimulus being the determinant factor of the OCR, minimal, very gradual and gentle manipulation on the extraocular muscles is required to diminish the incidence or the intensity of the OCR and the occurrence of cardiac arrhythmias.

Well managed anaesthesia is equally important. Controlled ventilation must be preferred to spontaneous ventilation, at least immediately before and during the muscular traction. Hypercapnia may augment the incidence of the OCR and hypoxia must be prevented when facing the possibility of cardiac arrhythmias.

Routine use of intravenous antimuscarinic drugs for the prevention of the OCR deserves more attention.

Perfect co-operation between the surgeon and the anaesthetist is mandatory. Both must realize the importance of the different factors causing or favouring the OCR. If the OCR is elicited, the surgeon must release the traction, wait, then continue the operation with gentler manipulation.

\section{Acknowledgements}

We thank Mr. Urs Maag (Centre de Calcul de l'Université de Montréal), Mr. Philippe Moss (Biomedical engineer) and Doctor Pierre Bourgon (Ophthalmologist, Hôpital Sainte-Justine) for the invaluable assistance they gave us. Also, we extend a note of appreciation to the nurses of the operating room, to the anaesthetic and inhalotherapy staff, who devotedly assisted us.

\section{References}

1 Aschner $B$. Über einen bisher noch nicht beschriebenen Reflex von Auge auf Krieslauf und Atmung: Verschinden des Radialispulses bei Druk auf das Auge. Wein Klin Wschr 1908; 21: 1529-30.

2 Dagnini, G. Intomo ad un riflesso provocato in alcuni emiplegici collo stimolo della comea c colla pressione sul bulbo oculare. Boll Sci Med 1908; 8: 380-1.

3 Salamagne JC, Le reflexe oculo-cardiaque - 
L'anesthésie en Ophtalmologie - XXVII Congrès National d'Anesthésie et de Réanimation, Bordeaux, France. Pp $41-59$ (1979).

4 Katz RL, Bigger JT. Cardiac arrhythmias during anesthesia and operation. Anesthesiology 1970; 33: 193-213.

5 Schwartz $H$. Oculocardiac reflex: is prophylaxis necessary? In Mark LC and Ngai SH, Eds. Highlights of clinical anesthesiology. Pp 111-4. Harper and Row. N.Y. (1971).

6 Pontinen PJ. The importance of the oculocardiac reflex during ocular surgery. Acta Ophthal Suppl 1966; 86: 7-66.

7 Anderson RL. The blepharocardiac reflex. Arch Ophthal 1978; 96: 1418-20.

$8 \mathrm{Kwik}$ RSH. Marcus Gunn syndrome associated with an unusual oculo-cardiac reflex. Anaesthesia 1980; 35: 46-9.

9 Mougeot A, Duverger $P$. Bradycardie et réflexe oculo-cardiaque dans les traumatismes oculaires, crâniens, encéphaliques. Presse Méd 1917; 25: 730-2.

10 Bailey $J H$. The oculocardiac reflex: report of a case exhibiting a marked reaction following enuclea tion of the eye-ball. Am J Ophthal 1935; 18: 22-25.

11 Donlon JV.Jr. Anesthesia for eye, ear, nose and throat surgery, In Miller RD, Ed. Anesthesia Vol. II: 1272-73. Churchill Livingstone, N.Y. (1981).

12 Dewar KMS, Wishart HY. The oculocardiac reflex Proc Roy Soc Med 1976; 69: 373-4.

13 Rhode J, Grown E, Bajares C, Anselmi A, Capriles $M$, Rivas $C$. A study of electrocardiographic alterations oceuning during operations on the extraocular muscles. Am J Ophthal 1958; 46: 367-82.

14 Bietti GB. Problems of anesthesia in strabismus surgery, Int Ophthal Clin 1973; 13(2): 727-37.

15 Cooper J, Medow N, Dibble C. Mortality rate in strabismus surgery. J Am Optom Assoc 1982; 53 : $391-5$.

16 Kirsch RE, Samet P, Kugel V, Axelrod S. Electrocardiographic changes during ocular surgery and their prevention by retrobulbar injection. Arch Oph thal 1957 ; 58 : 348-56.

17 Mallinson FB. Coombes SK. A hazard of anaesthesia in ophthalmic surgery. Lancet 1960; 1: 574-5.

18 Smith RB, Douglas H, Petruscak J. The oculocardiac reflex and sino-atrial artest. Can Anaesth Soc J 1972; 19: 138-42.

19 Landman ME, Ehrenfeld $D$. Ventricular fibrilla- tion following eyehall pressure in a case of paroxysmal supraventricular tachycardia. Am Heart J 1952; 43: $791-5$.

20 Sorenson EJ, Gilmore JE. Cardiac arrest during strabismus surgery - a preliminary report. Am J Ophthal 1956; 41: 748-52.

21 Sold M, Rothhammer A, Schafer WD. Atropine or glycopyrrolate for prevention of the oculocardiac reflex in children. A comparative study under standardized conditions. Gth Europ. Congress Anaesthesiology. Anaesthesia (Volume of Summaries): 494 (1982).

22 Alexander JP. Reflex disturbances of cardiac rhythm during ophthalmic surgery. Br J Ophthal 1975; 59: 518-24.

23 Moonie GT, Reer DL, Elton D. The oculocardiac reflex during strabismus surgery. Can Anacsth Soc J 1964; 11: 621-32.

24 Wethaf WR, Johnson DC. The oculocardiac reflex during extraocular muscle surgery. Arch $O$ phthal 1965; 73: 43-5.

25 Deacock $A R$, Oxer $H F$. The prevention of reflex bradycardia during ophthalmic surgery. Br J Anaesth 1962; 34: 451-7.

26 Apt $L_{1}$ Isenberg $S$, Gaffney WL. The oculocardiac reflex in strabismus surgery. Am J Ophthal 1973; 76: 533-6.

27 Berler DK. The oculocardiac reflex. Am J Ophthal 1963; 56: 954-9.

28 Mirakhur RK, Jones CJ, Dundee JW, Archer DB. I.M. or I.V. atropine or glycopyrrolate for the prevention of the oculocardiac reflex in children undergoing squint surgery. Br J Anaesth 1982; 54 1059-63.

29 Soliman MG, Laberge $R$. The use of the Bain circuit in spontaneously breathing paediatric patients. Can Anaesth Soc J 1978; 25: 276-81.

30 Steward $D J$. Manual of pediatric anesthesia. Longman Canada Lid., Don Mills, Ontario (1979).

31 Eger El. Atropine, scopolamine and related compounds. Anesthesiology 1962; $23: 365-83$.

32 Hunsley JE, Bush GH, Jones CI. A study of glycopyrrolate and atropine in the suppression of the oculocardiac reflex during strabismus surgery. Br J Anaesth 1982; 54; 459-64.

33 Mirakhur RK. Jones CJ. The oculocardiac reflex - pretreatment with atropine or glycopyrrolate in children. 6th Europ. Congress Anaesthesiology. Anacsthesia (Volume of Summarics); 286-7 (1982). 


\section{Résumé}

Les cuteurs décrivent une nouvelle méthode d' enregistrement grophique pour l'étude du réflexe oculocardiaque (ROC) et l'emploient chez 49 enfants (six mois d neuf ans; état physique ( de la classification ASA) soumis à des corrections de strabisme et anesthésiés à l'halothane en respiration spontanée. Les stimulations brusques et soutenues étaient définitivement plus réflexogènes que les stimulations progressives et délicates $(P=0.03)$. $L$ 'échappement vagal et la fatigue du ROC sont graphiquement documentés et analysés. L'emploi de stimulations a forme et à intensité bien définies rêvéta que le droit interne n'était pas plus réflexogène que les autres muscles extrinseques de l'ail. L'hypercapnie était un facteur adjurant important dans le déclenchement du ROC. La respiration contrólée est recommandée, au moins lors des iractions musculaires. L'usage routinier d'agents anticholinergiques par voie intraveineuse est brièvement discuté. La prophylaxie du ROC et la prophylaxie des arythmies cardiaques survenant au cours des corrections de strabisme, sont ainsi placées sur des bases plus rationnelles. 